\title{
Hypoxia promotes maintenance of the chondrogenic phenotype in rat growth plate chondrocytes through the HIF-1 $\alpha /$ YAP signaling pathway
}

\author{
HAO LI ${ }^{1}$, XIAOJUAN LI ${ }^{2}$, XINGZHI JING ${ }^{1}$, MI LI ${ }^{1}$, YE REN $^{1}$, JINGYUAN CHEN ${ }^{1}$, \\ CAIHONG YANG $^{1}$, HUA WU ${ }^{1}$ and FENGJING GUO ${ }^{1}$ \\ Departments of ${ }^{1}$ Orthopedics and ${ }^{2}$ Nephrology, Tongji Hospital, Tongji Medical College, \\ Huazhong University of Science and Technology, Wuhan, Hubei 430030, P.R. China
}

Received May 18, 2018; Accepted September 27, 2018

DOI: 10.3892/ijmm.2018.3921

\begin{abstract}
The Hippo-yes-associated protein (YAP) signaling pathway was previously identified to serve an important role in controlling chondrocyte differentiation and post-natal growth. Growth plate cartilage tissue is avascular, and hypoxia-inducible factor (HIF)- $1 \alpha$ is essential for chondrocytes to maintain their chondrogenic phenotype in a hypoxic environment. In the present study, the role of hypoxia and HIF-1 $\alpha$ in the regulation of YAP in chondrocytes was investigated. The data demonstrated that hypoxia promoted the maintenance of the chondrogenic phenotype, HIF-1 $\alpha$ expression and YAP activation in chondrocytes in a time-dependent manner. Hypoxia promoted YAP activation in a Hippo-independent manner. Inhibiting the expression of HIF-1 $\alpha$ decreased the activation of YAP and downregulated the expression of sex-determining region-box 9 protein (SOX9) under hypoxic conditions, while the upregulation of HIF-1 $\alpha$ by cobalt chloride promoted the expression and nuclear translocation of YAP and upregulated the expression of SOX9 and collagen II chain under normoxic conditions. In addition, inhibition of YAP expression under hypoxia did not affect the expression of the HIF-1 $\alpha$ signaling pathway, but inhibited the up-regulation of SOX9 expression caused by hypoxia. In addition, reoxygenation following hypoxia inhibited the activation of YAP caused by hypoxia in chondrocytes, whereas the upregulation of SOX9 and collagen II chain also appeared to be inhibited. In conclusion, the results of the present study demonstrated that hypoxia promoted YAP activation via HIF- $1 \alpha$. Therefore, the HIF-1 $\alpha /$ YAP signaling
\end{abstract}

Correspondence to: Professor Hua Wu or Professor Fengjing Guo, Department of Orthopedics, Tongji Hospital Tongji Medical College, Huazhong University of Science and Technology, 1095 Jiefang Avenue, Qiaokou, Wuhan, Hubei 430030, P.R. China E-mail:wuhua360@aliyun.com

E-mail: guofjdoc@163.com

Key words: hypoxia, hypoxia-inducible factor-1 $\alpha$, yes-associated protein, maintenance of the chondrogenic phenotype, chondrocytes axis may serve an important role in controlling growth plate chondrocyte differentiation and the maintenance of the chondrogenic phenotype in growth plate chondrocytes.

\section{Introduction}

Growth plate cartilage tissue is avascular, which restricts its repair capabilities; consequently, once this tissue is injured or degenerates, cartilage becomes difficult to repair. Cartilage tissue engineering includes autologous cell-based cartilage repair, which involves in vitro expansion of a sufficient number of chondrocytes to be implanted (1). However, chondrocytes are not able to maintain their phenotypic stability in vitro $(2,3)$ and lose the expression of sex-determining region-box 9 protein (SOX9) and cartilage-specific markers, including collagen II chain and aggrecan $(4,5)$. The development of strategies to promote the maintenance of the chondrogenic phenotype and induce re-expression of cartilage-specific markers in order to ensure regeneration of biochemically and mechanically functional cartilage tissue remains a difficult challenge. Due to the lack of vasculature in the growth plate of cartilage tissue, chondrocytes reside in a hypoxic microenvironment, with an oxygen content from $6 \% \mathrm{O}_{2}$ in the superficial zone to $1 \% \mathrm{O}_{2}$ in the deep zone, and accommodate physiological chronic hypoxia $(6,7)$. Hypoxic conditions have been demonstrated to promote the maintenance of the chondrogenic phenotype (8) and induce re-expression of cartilage-specific markers in chondrocytes $(9,10)$. Hypoxia has also been suggested to promote chondrogenic differentiation of stem cells through SOX9 mediation $(11,12)$ and inhibit chondrocyte hypertrophy (13). Hypoxia-inducible factors (HIFs), which consist of an oxygen-regulatory $\alpha$ subunit and a constitutively-expressed $\beta$ subunit, participate in the response of cells to hypoxia. Under normoxic conditions, the HIF- $\alpha$ subunit becomes hydroxylated by prolyl hydroxylases, followed by proteasome degradation; conversely, under hypoxic conditions, HIF- $\alpha$ is stabilized, forms a heterodimer with the HIF- $\beta$ subunit in the nucleus and drives the expression of its targets (14). All of the known HIFs (HIF-1, 2 and 3) are involved in the regulation of the chondrogenic phenotype under hypoxic conditions $(6,15,16)$. HIF-1 $\alpha$ has been indicated to be a critical survival factor for 
chondrocytes during development (6) by inducing expression of cartilage-specific markers $(17,18)$.

Cartilage tissue is regulated by various endocrine, paracrine and complex local signaling pathways (19). With the exception of HIF-1 $\alpha$, the other signaling pathways involved in the maintenance of the chondrogenic phenotype under hypoxic conditions remain largely unknown. The present study investigated the role of Yes-associated protein (YAP) in the maintenance of the chondrogenic phenotype in chondrocytes under hypoxic conditions. The Hippo-YAP signaling pathway serves an important role in regulating cell growth and differentiation (20). Core components of the Hippo pathway include the kinases mammalian Ste20 (MST) and serine/threonine-protein kinase large tumor suppressor (LATS). Upon activation of the Hippo pathway, MST phosphorylates and activates LATS, which subsequently phosphorylates and inhibits YAP. Phosphorylation of YAP leads to its cytoplasmic retention and degradation by proteasomes. Conversely, inhibition of the Hippo pathway results in YAP nuclear retention and activation of transcriptional activity (21). In addition to the Hippo signaling pathway, one previous study indicated that a number of signaling pathways interact with YAP protein and serve important roles in regulating YAP protein activation (22). To the best of our knowledge, the interaction between hypoxia and YAP has not been examined in growth plate chondrocytes. We hypothesized that hypoxia may activate YAP in chondrocytes; the possible role of hypoxia-induced activation of YAP in the maintenance of the chondrogenic phenotype and re-expression of cartilage-specific markers was then investigated, including the interaction between YAP and HIF-1 $\alpha$ under hypoxic conditions. The aim of the present study was to improve the current knowledge on signaling mechanisms in chondrocytes under hypoxic conditions, in order to improve the success of cartilage tissue engineering.

\section{Materials and methods}

Chondrocytes isolation and culture. Growth plate chondrocytes were obtained from 7-day old Sprague Dawley (SD) rats $(\mathrm{n}=20,12 \mathrm{~g})$. These SD rats were provided by the Experimental Animal Center of Tongji Hospital (Wuhan, Hubei, China) and maintained at $25^{\circ} \mathrm{C}$, a relative humidity of $60 \%$ and ad libitum access to food and water. The present study was approved by the Experimental Animal Ethics Committee of Tongji Hospital, Tongji Medical College of Huazhong University of Science and Technology (Wuhan, Hubei, China). Briefly, after the SD rats were sacrificed by cervical dislocation following anesthesia using sodium pentobarbital, cartilage was obtained from the growth plate of the distal femur and proximal tibia. Cartilage pieces were digested with $0.25 \%$ trypsin (Gibco; Thermo Fisher Scientific, Inc., Waltham, MA, USA) for $30 \mathrm{~min}$ at $37^{\circ} \mathrm{C}$ with gentle shaking, and then digested with $0.1 \%$ collagenase (Invitrogen; Thermo Fisher Scientific, Inc.) for $8 \mathrm{~h}$ at $37^{\circ} \mathrm{C}$. Single cells were collected with a cell strainer, followed by centrifugation $\left(350 \mathrm{xg}\right.$ and $25^{\circ} \mathrm{C}$ for $8 \mathrm{~min}$ ) and resuspension in Dulbecco's modified eagle's medium/Ham's F-12 (DMEM/F-12; HyClone; GE Healthcare Life Sciences, Logan, UT, USA) supplemented with $10 \%$ fetal bovine serum (FBS; Gibco; Thermo Fisher Scientific, Inc.) and $1 \%$ penicillin-streptomycin. A total of $5 \times 10^{5}$ chondrocytes were seeded into a cell medium and the medium was changed every 2 days. The chondrocytes were passaged at $80 \%$ confluence up to passage 3 .

Hypoxia intervention. Once the chondrocytes had reached $80 \%$ confluence, the cells were cultured under normoxic $\left(21 \% \mathrm{O}_{2}\right.$, $74 \% \mathrm{~N}_{2}, 5 \% \mathrm{CO}_{2}, 37^{\circ} \mathrm{C}$, saturated humidity) or hypoxic $\left(1 \% \mathrm{O}_{2}\right.$, $94 \% \mathrm{~N}_{2}, 5 \% \mathrm{CO}_{2}, 37^{\circ} \mathrm{C}$, saturated humidity) conditions.

Drugs treatments and RNA interference. Chondrocyte culture medium was supplemented with different concentrations of cobalt chloride (0, 50, 10, 150 and $200 \mu \mathrm{M}$; Sigma-Aldrich; Merck KGaA, Darmstadt, Germany) for the indicated times. When the growth plate chondrocytes had reached $~ 50 \%$ confluence, the original culture medium was discarded, and OPTIMEM medium containing YAP small interfering (si)RNA (50 nM), HIF-1 $\alpha$ siRNA (50 nM; Guangzhou Ribobio Co., Ltd., Guangzhou, Guangdong, China) or negative control (NC) siRNA, and Lipofectamine $2000^{\circledR}$ (Invitrogen; Thermo Fisher Scientific, Inc.), was transfected in chondrocytes for $6 \mathrm{~h}$. The sequences of YAP siRNA were as follows: GCCATG AACCAGAGGATCA. The sequences of HIF-1 $\alpha$ siRNA were as follows: CTGATAACGTGAACAAATA, TCGACAAGC TTAAGAAAGA and GGACAATATAGACATT. Subsequent experiments were performed after $24 \mathrm{~h}$. Endogenous YAP and HIF-1a protein knock-out efficiency was examined by western blot analysis.

Western blot analysis. Following rinsing with pre-cooled PBS, the chondrocytes were lysed with radioimmunoprecipitation assay lysis buffer (Boster Biological Technology, Inc., Wuhan, Hubei, China) containing protease inhibitors and phosphatase inhibitors for $30 \mathrm{~min}$, and the lysate was centrifuged at $12,000 \mathrm{x} \mathrm{g}$ at $4^{\circ} \mathrm{C}$ for $20 \mathrm{~min}$. Subsequent to collection of the supernatant, the protein concentration was determined by a bicinchoninic acid assay. A total of $20 \mu \mathrm{g}$ protein was loaded in 10\% Bis-Tris gels. Following electrophoresis, the separated proteins were transferred onto a polyvinylidene fluoride membrane. The membranes were blocked with 5\% BSA (Biosharp, Inc., Hefei, Anhui, China) for $1 \mathrm{~h}$ at room temperature and incubated with the primary antibodies overnight at $4^{\circ} \mathrm{C}$, followed by rinsing with TBS supplemented with $0.1 \%$ Tween-20 (TBST) and incubation with horseradish peroxidase-conjugated goat anti-mouse or goat anti-rabbit secondary antibody (cat no. BA1050 and BA1054, respectively; both 1:5,000 dilution; Boster Biological Technology) for $1 \mathrm{~h}$ at room temperature. Then, following rinsing again with TBST, exposure was performed using an electrochemiluminescence (ECL) substrate (Pierce; Thermo Fisher Scientific, Inc.) with a Bio-Rad exposure machine (Bio-Rad Laboratories, Inc., Hercules, CA, USA). Gray-scale analysis was performed using Quantity One software version 5.1 (Bio-Rad Laboratories, Inc.) to determine the relative expression of various target proteins, and $\beta$-actin was used as an internal control. The primary antibodies used were as follows: MST1 (cat. no. 3682; 1:1,000 dilution; Cell Signaling Technology, Inc., Danvers, MA, USA), phosphorylated (p)-LATS (cat. no. 9157; 1:1,000 dilution; Cell Signaling Technology, Inc.), LATS (cat. no. 3477; 1:1,000 dilution; Cell Signaling Technology, Inc.), p-YAP (cat. no. 13008; 1:500 dilution; Cell Signaling Technology, Inc.), YAP (cat. no. 14074; 1:500 dilution; Cell Signaling Technology, Inc.), 
SOX9 (cat. no. ab3697; 1:5,000 dilution; Abcam, Cambridge, MA, USA), collagen II chain (cat. no. ab34712; 1:1,000 dilution; Abcam), aggrecan (cat. no. ab36861; 1:1,000 dilution; Abcam) HIF-1 $\alpha$ (cat. no. ab2185; 1:500 dilution; Abcam), vascular endothelial growth factor (VEGF; cat. no. ab46154; 1:1,000 dilution; Abcam); connective tissue growth factor (CTGF; cat. no. ab6992; 1:1,000 dilution; Abcam), PCNA (cat. no. 13110; 1:1,000 dilution; Cell Signaling Technology, Inc.), VEGF receptor 1 (cat. no. ab32152, 1:1,000 dilution; Abcam) and $\beta$-actin (cat. no. BM5180; 1:400 dilution; Boster Biological Technology).

Immunofluorescence. The chondrocytes were rinsed three times with PBS, fixed with $4 \%$ paraformaldehyde for $15 \mathrm{~min}$ at room temperature, permeabilized with $0.1 \%$ Triton X-100 for $5 \mathrm{~min}$ and blocked with $0.1 \% \mathrm{BSA}$ for $1 \mathrm{~h}$ at room temperature. The cells were incubated with the primary antibodies (YAP, cat no. 14074; 1:200 dilution; Cell Signaling Technology, Inc.; SOX9, cat. no. ab3697; 1:200 dilution; Abcam; collagen II chain, cat. no. ab34712; 1:200 dilution; Abcam; HIF-1 $\alpha$, cat. no. ab2185; 1:200 dilution; Abcam; VEGF, cat. no. ab46154; 1:00 dilution; Abcam) overnight at $4^{\circ} \mathrm{C}$. Following rinsing with PBS, the CY3-conjugated goat anti-rabbit immunoglobulin $\mathrm{G}$ (cat. no. BA1032; 1:100 dilution; Boster Biological Technology) was added and the cells were incubated for $1 \mathrm{~h}$ at room temperature. Following rinsing with PBS, DAPI (undiluted; cat. no. AR1176, Boster Biological Technology) was added to stain the nuclei for $5 \mathrm{~min}$ at room temperature. Subsequent to rinsing again, the cells were imaged using an EVOS FL auto fluorescence microscope (magnification x200; Thermo Fisher Scientific, Inc.).

Reverse transcription quantitative polymerase chain reaction (RT-qPCR). RT-qPCR was used for quantification of gene expression. Total RNA was isolated with the EZNA Total RNA kit (Omega Bio-Tek, Inc., Norcross, GA, USA) according to the manufacturer's protocol, and the A260/280 absorbance ratio of the samples was measured to determine the RNA quality. RNA was synthesized using the Reverse Transcription kit (Toyobo Life Science, Osaka, Japan) and single-stranded cDNA was stored at $-20^{\circ} \mathrm{C}$ until use. The SYBR Green Real-Time PCR Master Mix (Toyobo Life Science) was used to amplify the cDNA under the following conditions: 40 cycles of denaturation at $95^{\circ} \mathrm{C}$ for $30 \mathrm{sec}, 40$ cycles of amplification at $94^{\circ} \mathrm{C}$ for $5 \mathrm{sec}$, and at $58^{\circ} \mathrm{C}$ for $30 \mathrm{sec}$. $\beta$-actin served as an internal control. There were three duplicate wells/cDNA sample. The sequences of the primers were as follows: MST1 forward, 5'-CATGACTGCTGGGTCCTACA-3'; MST1 reverse, 5'-TGC ACGACCTTGTTAATCCA-3'; LATS1 forward, 5'-CAG CAACTACTCTGGCAGCA-3'; LATS1 reverse, 5'-TCGGTC GACATCTTGTTCAG-3'; LATS2 forward, 5'-ACAGAA GCAGCACCAGAGGT-3'; LATS2 reverse, 5'-CGACACTCC ACCAGTCACAG-3'; CTGF forward, 5'-GAGTCGTCTCTG CATGGTCA-3'; CTGF reverse, 5'-GCAGCCAGAAAGCTC AAACT-3'; YAP forward, 5'-TTTGCCATGAACCAGAG GAT-3'; YAP reverse, 5'-TATCTGCTGCTGCTGGTTTG-3'; SOX9 forward, 5'-TGCAGCACAAGA AAGACCAC-3'; SOX9 backward, 5'-TGGCGTTAGGAGAGATGTGA-3'; collagen $\alpha$-1(II) chain forward, 5'-CTCAAGTCGCTGAAC AACCA-3'; collagen $\alpha-1$ (II) chain reverse, 5'-CTCAAGTCG CTGAACAACCA-3'; aggrecan forward, 5'-AACTCAGTG
GCCAAACATCC-3'; aggrecan reverse, 5'-AACTCAGTG GCCAAACATCC-3'; HIF-1 $\alpha$ forward, 5'-TCAAGTCAGCAA CGTGGAAG-3'; HIF-1 $\alpha$ reverse, 5'-GGCCAGCTAACTTTC AGCAC-3'; VEGFa forward, 5'-GCTTCCTAGTGGGCTCTG TG-3'; VEGFa reverse, 5'-CACACATACACTCCGGCATC-3'; CTGF forward, 5'-GAGTCGTCTCTGCATGGTCA-3'; CTGF reverse, 5'-GCAGCCAGAAAGCTCAAACT-3'; $\beta$-actin forward, 5'-GAGATTACTGCCCTGGCT CCTAGC-3'; $\beta$-actin reverse, 5'-CCGGACTCATCGTACTCCTGCTT-3'.

Statistical analysis. All experiments were repeated three times and the results are presented as mean \pm standard deviation. SPSS statistical software (v.19.0; IMB Corp., Armonk, NY, USA) was used to analyze statistical differences between groups. An unpaired Student's t-test was used to assess statistical significance between two groups. A one-way analysis of variance with Bonferroni post-hoc test was used for multiple group comparisons. $\mathrm{P}<0.05$ was considered to indicate a statistically significant difference.

\section{Results}

Hypoxia promotes YAP activation in growth plate chondrocytes via a Hippo-independent signaling pathway. To explore the effect of hypoxia $\left(1 \% \mathrm{O}_{2}\right)$ on YAP activation in growth plate chondrocytes at different time points, western blot analysis, PCR and immunofluorescence were used. As indicated in Fig. 1A-C, hypoxia significantly promoted YAP mRNA and protein expression. As the total YAP protein level was altered following hypoxia treatment, the ratio of $\mathrm{p}-\mathrm{YAP} /$ total YAP was used to analyze YAP activation. As demonstrated in Fig. 1A, hypoxia promoted YAP dephosphorylation in a time-dependent manner. Similar results were also obtained by immunofluorescence. As serum contains lysophosphatidic acid, which is able to activate YAP protein, chondrocytes were serum-starved for $24 \mathrm{~h}$. As indicated in Fig. 1D, immunofluorescence imaging of chondrocytes cultured under normoxia revealed that YAP was inactivated and primarily located in the cytoplasm of chondrocytes. Following culture under hypoxic conditions for $4 \mathrm{~h}$, the YAP protein was activated and translocated into the nucleus. These results indicated that hypoxia activated YAP protein.

The Hippo signaling pathway serves an important role in regulating YAP protein activation. Therefore, whether hypoxia promoted YAP activation via inhibiting the Hippo signaling pathway was next investigated. The expression levels of core regulators in the Hippo-YAP signaling pathway including MST1, p-LATS and LATS were assessed. The western blot analysis results demonstrated that, when chondrocytes were cultured under hypoxic conditions, the Hippo signaling pathway was activated and an increase in MST1 mRNA and protein expression was observed (Fig. 1A-C). Furthermore, the ratio of p-LATS/LATS was significantly upregulated under exposure to hypoxic conditions for $>4 \mathrm{~h}$ (Fig. 1B). As Hippo signaling pathway activation may result in YAP protein phosphorylation and cytoplasm retention, hypoxia may therefore promote YAP activation in a Hippo-independent manner.

Hypoxia promotes the expression of cartilage-specific markers at the protein and gene level. The effect of hypoxia 


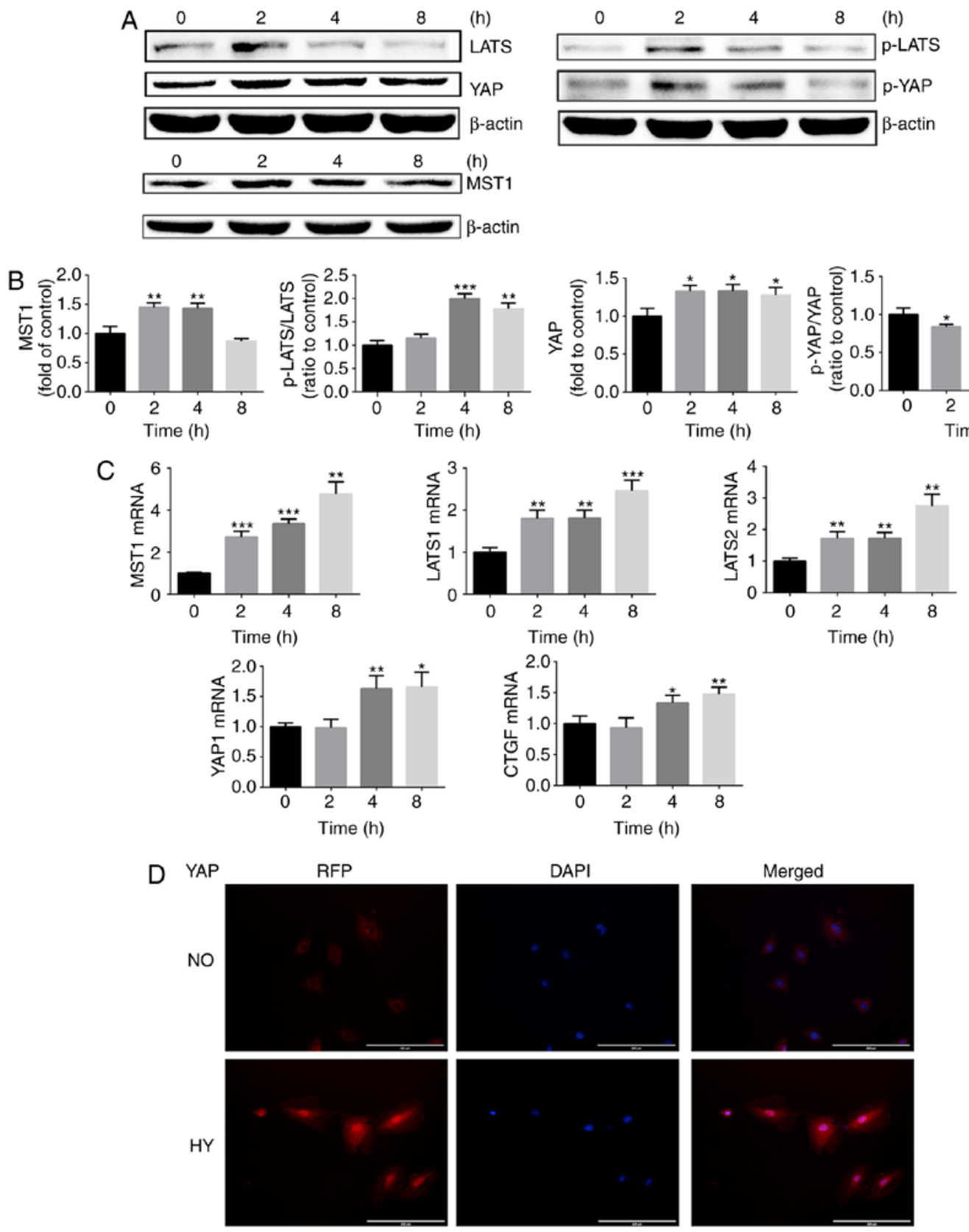

Figure 1. Hypoxia promotes YAP activation in growth plate chondrocytes via a Hippo-independent signaling pathway. (A) Protein expression of MST1, p-LATS, LATS, p-YAP and YAP of growth plate chondrocytes cultured under hypoxia $\left(1 \% \mathrm{O}_{2}\right)$ for $0,2,4$ and $8 \mathrm{~h}$. $\beta$-actin served as an internal control. (B) The density of the bands were quantified and normalized to the control group (0 h). (C) mRNA expression of MST1, LATS1, LATS2, YAP and CTGF in chondrocytes cultured under hypoxia $\left(1 \% \mathrm{O}_{2}\right)$ for $0,2,4$ and $8 \mathrm{~h}$. (D) Immunofluorescence imaging of YAP (red) in chondrocytes cultured under normoxia $\left(21 \% \mathrm{O}_{2}\right)$ or hypoxia $\left(1 \% \mathrm{O}_{2}\right)$ for $4 \mathrm{~h}$. DAPI (blue) was used for nuclear staining. Scale bar=200 $\mu \mathrm{m}$. Data are presented as mean \pm standard deviation $(\mathrm{n}=3)$ and normalized to the control group $(0 \mathrm{~h}) .{ }^{*} \mathrm{P}<0.05,{ }^{* * *} \mathrm{P}<0.01$ and ${ }^{* * * *} \mathrm{P}<0.001$ vs. the control group $(0 \mathrm{~h})$. YAP, Yes-associated protein; MST1, mammalian Ste20; LATS1/2, serine/threonine protein kinase large tumor suppressor 1/2; p, phosphorylated; CTGF, connective tissue growth factor; NO, normoxia; HY, hypoxia; RFP, red fluorescent protein.

on the protein and gene expression of cartilage-specific markers in chondrocytes under normoxic $\left(21 \% \mathrm{O}_{2}\right)$ or hypoxic $\left(1 \% \mathrm{O}_{2}\right)$ conditions was then investigated. The expression of cartilage-specific markers, including SOX9, collagen II chain and aggrecan, was assessed. The protein expression levels of SOX9, collagen II chain and aggrecan were significantly increased in response to hypoxia in chondrocytes. Notably, when chondrocytes remained under hypoxic conditions for $8 \mathrm{~h}$, the protein expression levels of SOX9, collagen II chain and aggrecan were downregulated compared with that at
$4 \mathrm{~h}$, but the expression level of SOX9 and collagen II chain remained increased compared with that in the control group (Fig. 2A and B).

The RT-qPCR results demonstrated that hypoxia promoted SOX9, collagen $\alpha-1$ (II) chain and aggrecan gene expression, and the mRNA levels of SOX 9 and aggrecan peaked at $4 \mathrm{~h}$ (Fig. 2C).

The expression levels of SOX9 and collagen II chain were then investigated by immunofluorescence. Concordant with the protein and gene expression data, SOX9 and collagen II 

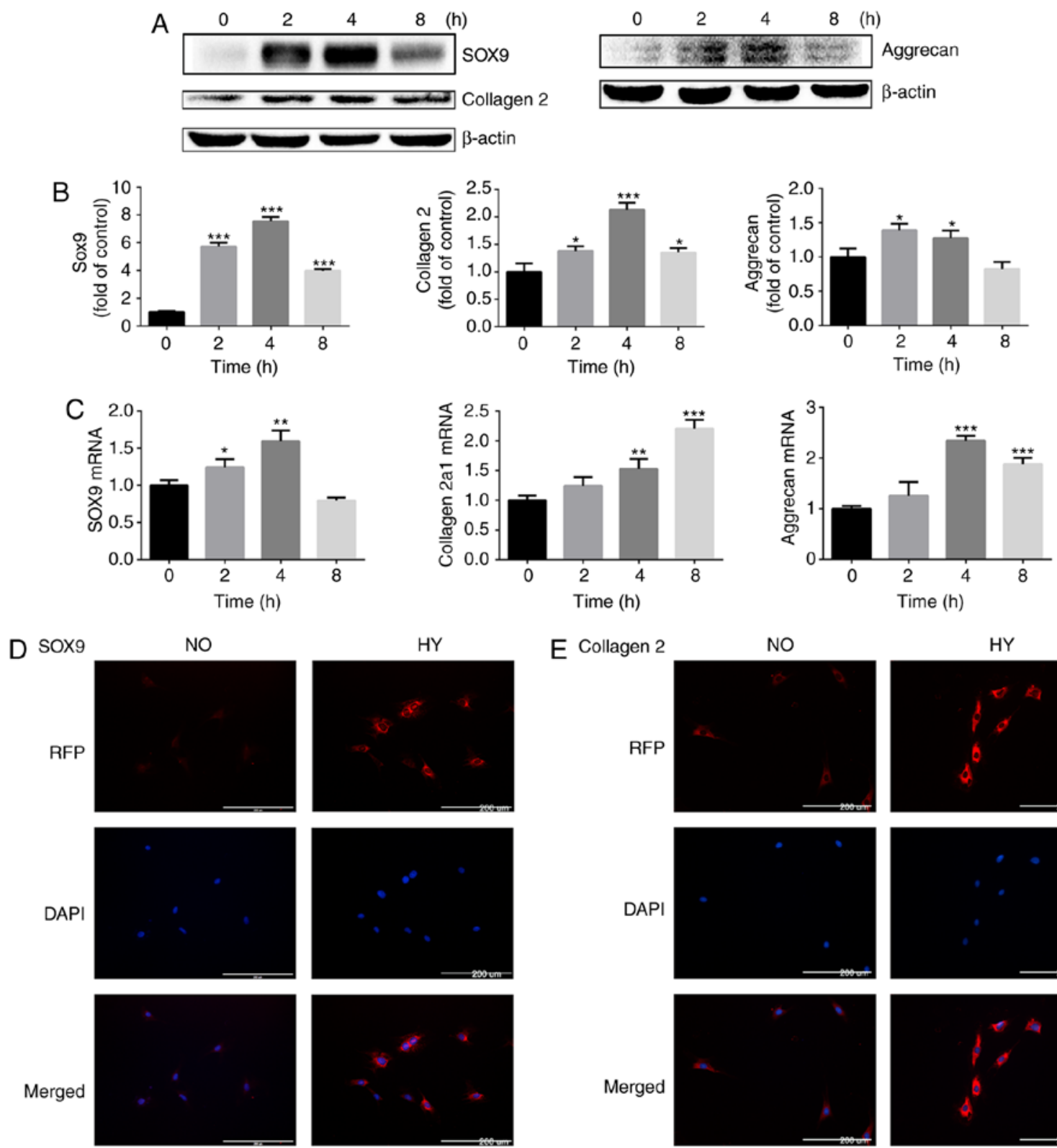

E Collagen 2

NO
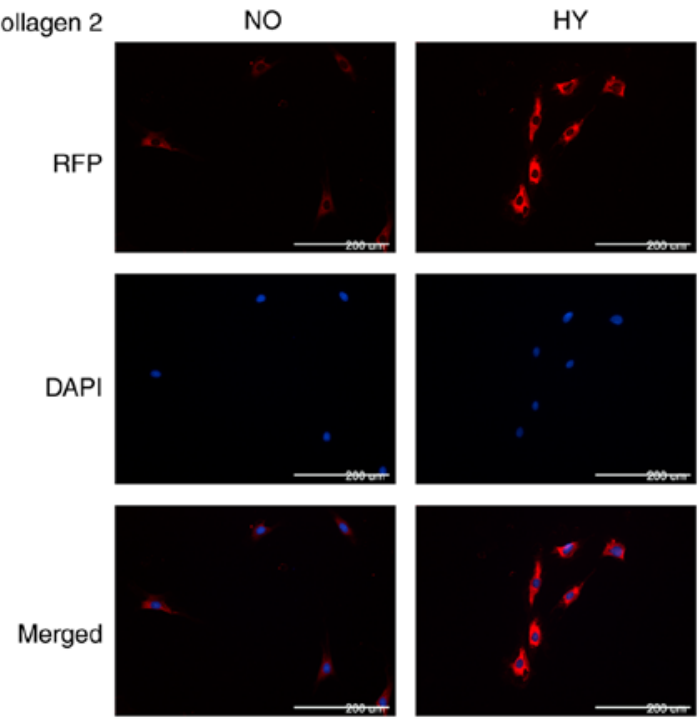

Figure 2. Hypoxia promotes the expression of cartilage-specific markers at the protein and gene levels. (A) Protein expression of SOX9, collagen II chain and aggrecan in growth plate chondrocytes cultured under hypoxia $\left(1 \% \mathrm{O}_{2}\right)$ for $0,2,4$ and $8 \mathrm{~h}$. $\beta$-actin served as an internal control. (B) The density of the bands was quantified and normalized to the control group $(0 \mathrm{~h})$. (C) mRNA expression of SOX9, collagen $\alpha-1$ (II) chain and aggrecan in chondrocytes cultured under hypoxia $\left(1 \% \mathrm{O}_{2}\right)$ for $0,2,4$ and $8 \mathrm{~h}$. (D) Immunofluorescence imaging of SOX9 (red) of chondrocytes cultured under normoxia $\left(21 \% \mathrm{O}_{2}\right)$ or hypoxia $\left(1 \% \mathrm{O}_{2}\right)$ for $4 \mathrm{~h}$. DAPI (blue) was used for nuclear staining. Scale bar=200 $\mu \mathrm{m}$. (E) Immunofluorescence imaging of collagen II chain (red) in chondrocytes cultured under normoxia $\left(21 \% \mathrm{O}_{2}\right)$ or hypoxia $\left(1 \% \mathrm{O}_{2}\right)$ for $4 \mathrm{~h}$. DAPI (blue) was used for nuclear staining. Scale bar $=200 \mu \mathrm{m}$. Data are presented as mean \pm standard deviation $(\mathrm{n}=3)$ and normalized to the control group $(0 \mathrm{~h}) .{ }^{*} \mathrm{P}<0.05,{ }^{* *} \mathrm{P}<0.01$ and ${ }^{* * *} \mathrm{P}<0.001$ vs. the control group $(0 \mathrm{~h})$. SOX9, sex-determining region-box 9 protein; NO, normoxia; HY, hypoxia; RFP, red fluorescent protein.

chain deposition in chondrocytes was markedly increased by exposure to hypoxia for $4 \mathrm{~h}$ (Fig. 2D and E).

These results indicate that hypoxia induces the expression of cartilage-specific markers in chondrocytes, thereby promoting the maintenance of the chondrogenic phenotype.

Hypoxia promotes YAP activation in a HIF-1 $\alpha$ dependent manner. HIF-1 $\alpha$ is key to chondrocyte survival under hypoxic conditions. Therefore, the contribution of HIF-1 $\alpha$ to hypoxia-induced activation of YAP and maintenance of the chondrogenic phenotype in chondrocytes was investigated. Firstly, the expression of HIF-1 $\alpha$ and its downstream target gene VEGF was examined in a hypoxic microenvironment. The protein expression of HIF-1 $\alpha$ in growth plate chondrocytes was significantly increased under hypoxia, and VEGF protein expression was also significantly upregulated (Fig. 3A and B). The RT-qPCR analysis yielded the same results (Fig. 3C). Similar results were also obtained by immunofluorescence assay (Fig. 3D and E).

Next, siRNA were used to destabilize HIF-1 $\alpha$ under hypoxic conditions and detect the activation of YAP. As indicated in Fig. 3F, all three siRNA sequences effectively downregulated the expression of HIF-1 $\alpha$, with sequence 2 being the most effective (Fig. 3F and G). Following inhibition of HIF-1 $\alpha$ expression 
A

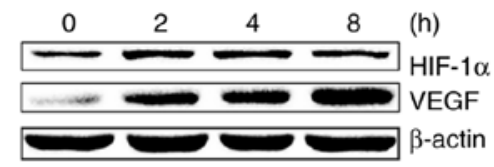

B
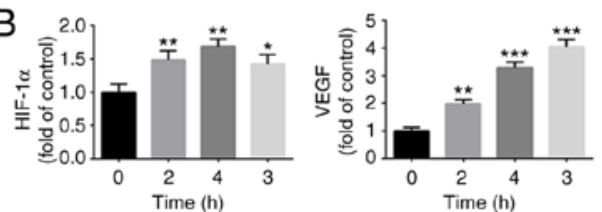

C
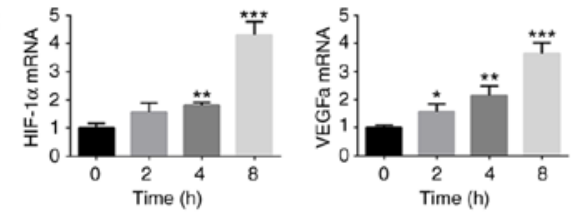

D HIF-1 $\alpha$

NO
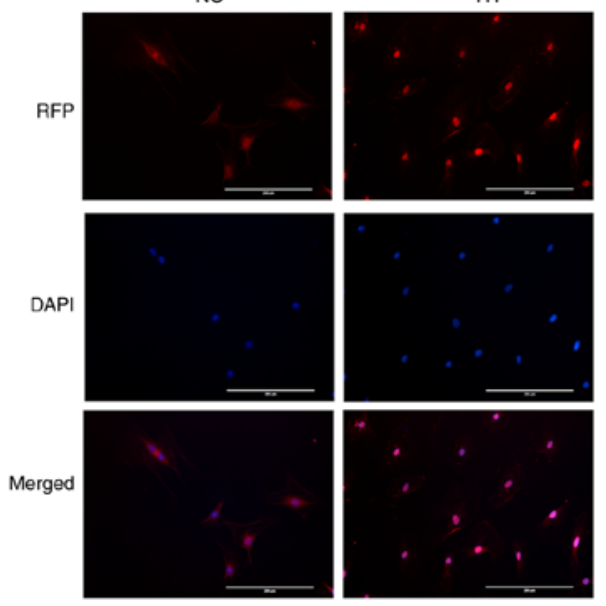

E
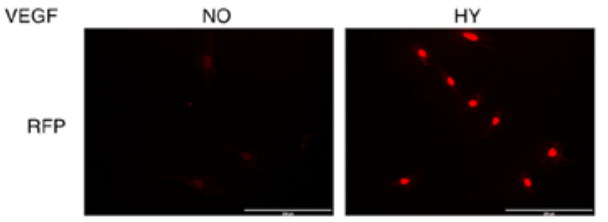

DAPI
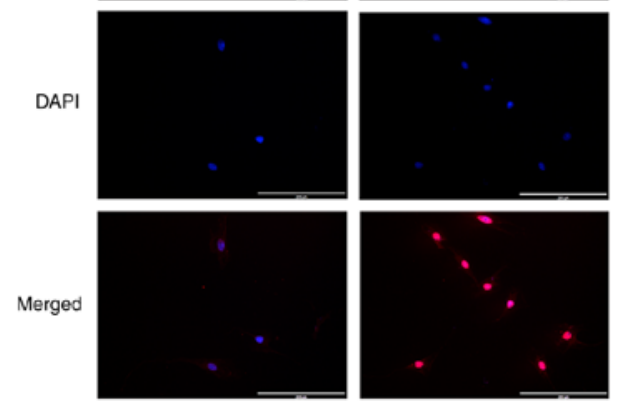

$\mathrm{F}$

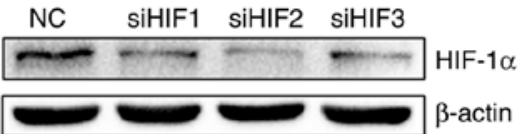

G

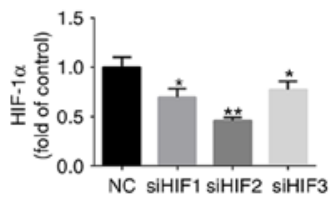

$\mathrm{H}$

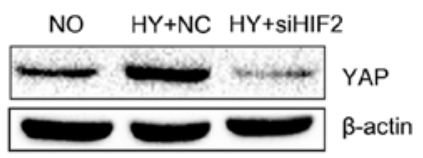

।

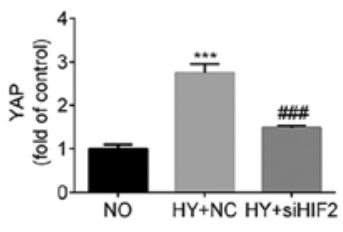

$J$

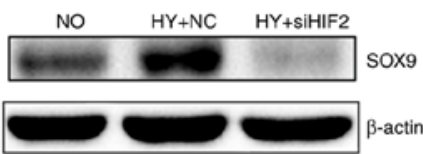

K

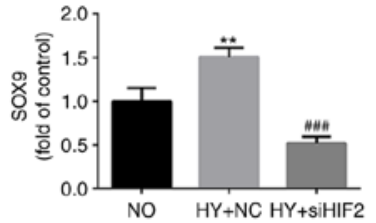

L
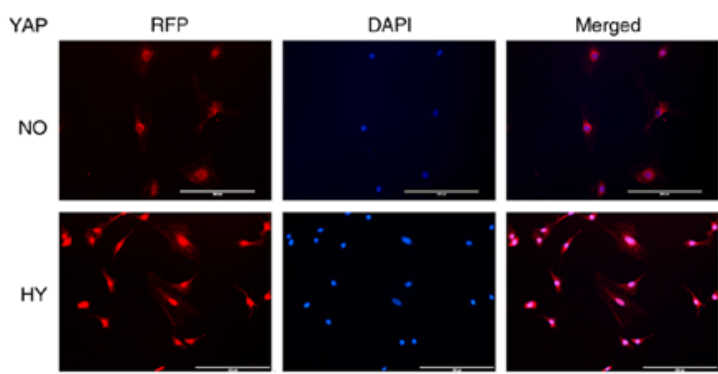

$H Y+\operatorname{siH} I F-10$
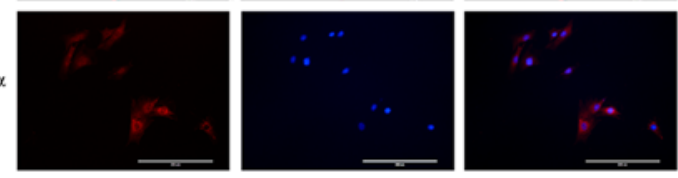

Figure 3. HY promotes YAP activation in a HIF-1 $\alpha$-dependent manner. (A) Protein expression of HIF-1 $\alpha$ and VEGF in growth plate chondrocytes cultured under $\mathrm{HY}\left(1 \% \mathrm{O}_{2}\right)$ for $0,2,4$ and $8 \mathrm{~h}$. $\beta$-actin served as an internal control. (B) The density of the bands were quantified and normalized to the control group (0 h). (C) mRNA expression of HIF-1 $\alpha$ and VEGF in chondrocytes cultured under HY (1\% $\mathrm{O}_{2}$ ) for $0,2,4$ and $8 \mathrm{~h}$. (D) Immunofluorescence imaging of HIF-1 $\alpha$ (red) in chondrocytes cultured under $\mathrm{NO}\left(21 \% \mathrm{O}_{2}\right)$ or $\mathrm{HY}\left(1 \% \mathrm{O}_{2}\right)$ for $4 \mathrm{~h}$. DAPI (blue) was used for nuclear staining. Scale bar=200 $\mu \mathrm{m}$. (E) Immunofluorescence imaging of VEGF (red) in chondrocytes cultured under NO $\left(21 \% \mathrm{O}_{2}\right)$ or $\mathrm{HY}\left(1 \% \mathrm{O}_{2}\right)$ for $4 \mathrm{~h}$. DAPI (blue) was used for nuclear staining. Scale bar $=200 \mu \mathrm{m}$. (F) Protein expression of HIF-1 $\alpha$ in growth plate chondrocytes following siRNA silencing of HIF-1 $\alpha$ and then culture under $\mathrm{HY}\left(1 \% \mathrm{O}_{2}\right.$ ) for 4 h to detect the effect of HIF-1 $\alpha$ silencing. $\beta$-actin served as an internal control. (G) The density of the bands was quantified and normalized to the NC group. Data are presented as mean $\pm \mathrm{SD}(\mathrm{n}=3)$. ${ }^{*} \mathrm{P}<0.05$ and ${ }^{* *} \mathrm{P}<0.01$ vs. the NC group. $(\mathrm{H})$ Protein expression of YAP in growth plate chondrocytes cultured under NO or under $\mathrm{HY}$ with siRNA negative control (HY+NC group) or under HY with siHIF2 siRNA (HY+siHIF2 group) for 4 h. $\beta$-actin served as an internal control. (I) The density of the bands was quantified and normalized to the NO group. (J) Protein expression of SOX9 in growth plate chondrocytes cultured under NO (NO group) or under HY with siRNA negative control (HY+NC group) or under HY with siRNA siHIF2 (HY+siHIF2 group) for 4 h. $\beta$-actin served as an internal control. (K) The density of the bands was quantified and normalized to the NO group. ${ }^{* *} \mathrm{P}<0.01 \mathrm{vs}$. the NO group. (L) Immunofluorescence imaging of YAP (red) in chondrocytes cultured under $\mathrm{NO}\left(21 \% \mathrm{O}_{2}\right)$ or $\mathrm{HY}\left(1 \% \mathrm{O}_{2}\right)$ with or without siHIF-1 $\alpha$ for $4 \mathrm{~h}$. DAPI (blue) was used for nuclear staining. Scale bar=200 $\mu \mathrm{m}$. Data are presented as mean \pm standard deviation $(\mathrm{n}=3)$, and normalized to the control $(0 \mathrm{~h}) / \mathrm{NC}$ groups. ${ }^{*} \mathrm{P}<0.05,{ }^{* * *} \mathrm{P}<0.01$ and ${ }^{* * * *} \mathrm{P}<0.001$ vs. the control $(0 \mathrm{~h})$ or $\mathrm{NC}$ groups. ${ }^{\# \# \#} \mathrm{P}<0.001$ vs. the HY+NC group. YAP, yes-associated protein; HIF-1 $\alpha$, hypoxia-inducible factor $1 \alpha$; SOX9, sex-determining region-box 9 protein; siRNA, small interfering RNA; NO, normoxia; HY, hypoxia; RFP, red fluorescent protein; VEGF, vascular endothelial growth factor; NC, negative control. 
by siRNA, it was identified that the activation of YAP protein induced by hypoxia was significantly inhibited (Fig. 3H and I). It was also identified that, following downregulation of HIF-1 $\alpha$ expression, the upregulation of SOX9 caused by hypoxia was also significantly downregulated (Fig. 3J and K). To additionally investigate the effect of HIF-1 $\alpha$ on YAP localization and activation, an immunofluorescence assay was conducted. As demonstrated in Fig. 3L, HIF-1 $\alpha$ siRNA treatment significantly abolished hypoxia-induced YAP nucleus translocation and activation (Fig. 3L).

These results suggest that HIF-1 $\alpha$ serves an important role in regulating chondrocyte differentiation. Notably, the results of the present study also indicate that hypoxia-induced YAP activation is HIF-1 $\alpha$-dependent.

Cobalt chloride upregulates HIF-1 $\alpha$ expression and promotes activation of YAP. To additionally explore the effect of HIF-1 $\alpha$ on YAP activation under normoxia, chondrocytes were treated with cobalt chloride to stabilize HIF-1 $\alpha$ under normoxic conditions. Following treatment with different concentrations of cobalt chloride $(0-200 \mu \mathrm{M})$ for $24 \mathrm{~h}$, the gene and protein expression of HIF-1 $\alpha$ and its downstream target, VEGF, were evaluated by western blot analysis and RT-qPCR. The protein expression of HIF-1 $\alpha$ was significantly upregulated following stimulation of chondrocytes with different concentrations of cobalt chloride, and VEGF expression was also upregulated (Fig. 4A and B). At cobalt chloride concentrations of $>100 \mu \mathrm{M}$, the HIF-1 $\alpha$ and VEGFa gene expressions were significantly increased compared with those in the control group (Fig. 4C).

Next, $100 \mu \mathrm{M}$ cobalt chloride was used to stimulate growth plate chondrocytes for different lengths of time, and the changes in HIF-1 $\alpha$ and VEGF protein levels were assessed. The protein expression of HIF-1 $\alpha$ was significantly upregulated following stimulation of chondrocytes with $100 \mu \mathrm{M}$ cobalt chloride for 12-48 h. The protein expression of VEGF also exhibited a significant upregulation (Fig. 4D and E).

Then, the activation of YAP in the presence of cobalt chloride under normoxia was examined. Different concentrations of cobalt chloride $(0-200 \mu \mathrm{M})$ were used to stimulate chondrocytes for $24 \mathrm{~h}$ under normoxia, and the gene and protein expression levels of YAP and its downstream target gene, CTGF, were detected. As demonstrated in Fig. 4F-H, cobalt chloride significantly promoted YAP activation and the expression of CTGF. Cobalt chloride $(100 \mu \mathrm{M})$ was used to stimulate growth plate chondrocytes for different time intervals, and the changes in YAP and CTGF protein levels were assessed (Fig. 4I and J). The results of immunofluorescence also revealed that $100 \mu \mathrm{M}$ cobalt chloride significantly promoted YAP protein expression and nuclear translocation (Fig. 4K). These results indicated that the upregulation of HIF- $1 \alpha$ with cobalt chloride promoted the activation of YAP under normoxic conditions.

HIF-1 $\alpha$ is useful for maintaining of the chondrogenic phenotype. Chondrocytes were then treated with cobalt chloride to stabilize HIF-1 $\alpha$ under normoxia and the expression of cartilage-specific markers was detected. The western blot analysis results demonstrated that treatment with cobalt chloride at different concentrations for $24 \mathrm{~h}$ upregulated the protein expression of SOX9 and collagen II chain in chondrocytes, with $100 \mu \mathrm{M}$ cobalt chloride exerting the most marked effect (Fig. 5A and B). The RT-qPCR results also revealed that cobalt chloride stimulated the gene expression of collagen $\alpha-1$ (II) chain, aggrecan and SOX9 (Fig. 5C). Subsequently, the chondrocytes were stimulated with $100 \mu \mathrm{M}$ cobalt chloride for different time intervals. The protein expression levels of collagen II chain and SOX9 were significantly increased following stimulation with $100 \mu \mathrm{M}$ cobalt chloride (Fig. 5D and E). The aforementioned results indicated that increasing the expression of HIF-1 $\alpha$ with cobalt chloride in a normoxic environment effectively promoted the expression of cartilage-specific markers in chondrocytes, which was beneficial in promoting the maintenance of the chondrogenic phenotype.

Effect of YAP on HIF-1 $\alpha$ and the maintenance of the chondrogenic phenotype. To investigate the role of YAP in HIF-1 $\alpha$ and the maintenance of the chondrogenic phenotype in chondrocytes under hypoxic conditions, siRNA were used to downregulate the expression of YAP and investigate the expression of SOX9 and HIF-1 $\alpha$ in chondrocytes exposed to hypoxia. SOX9 protein expression was downregulated following YAP inhibition. However, the levels of HIF-1 $\alpha$ and VEGF did not change significantly (Fig. 6A-C). The results demonstrated that YAP is implicated in the maintenance of the chondrogenic phenotype of chondrocytes induced by hypoxia, and the downregulation of YAP expression did not affect the expression of HIF-1 $\alpha$ under hypoxia.

To investigate whether reoxygenation following hypoxia may inhibit the maintenance of the chondrogenic phenotype, the chondrocytes were stimulated by normoxia for $1 \mathrm{~h}$, following hypoxia for $4 \mathrm{~h}$, to observe the expression of cartilage-specific markers and YAP. The western blot analysis revealed that the levels of SOX9 and collagen II chain in chondrocytes were downregulated during post-hypoxia reoxygenation. YAP exhibited the same trend. (Fig. 6D-F). Therefore, it was concluded that the upregulation of cartilage-specific markers caused by short-term hypoxia stimulation is reversible, and that this reversibility may be associated with inhibition of YAP by reoxygenation.

\section{Discussion}

Cartilage tissue is a special type of connective tissue that lacks vasculature; chondrocytes reside in a hypoxic microenvironment, and produce and maintain the extracellular matrix of cartilage, including collagen (primarily collagen II chain) and proteoglycans (primarily aggrecan). In vitro, chondrocytes are not able to maintain their phenotypic stability and may lose the expression of cartilage-specific markers including SOX9, collagen II chain and aggrecan $(4,5)$ due to the hyperoxic environment established in vitro relative to their physiological state. Therefore, understanding the signaling mechanisms that regulate the maintenance of the chondrogenic phenotype of chondrocytes is crucial for optimizing the cultivation of chondrocytes, in order to improve the strategies of autologous cell-based cartilage repair. In the present study, it was demonstrated that hypoxia promoted the activation of YAP in chondrocytes in a HIF-1 $\alpha$-dependent manner.

HIF is a type of transcriptional factor that mediates adaptation of mammalian cells to hypoxia, and consists of $\alpha$ and $\beta$ subunits. HIF-1 $\alpha$ is a functional subunit that determines HIF-1 

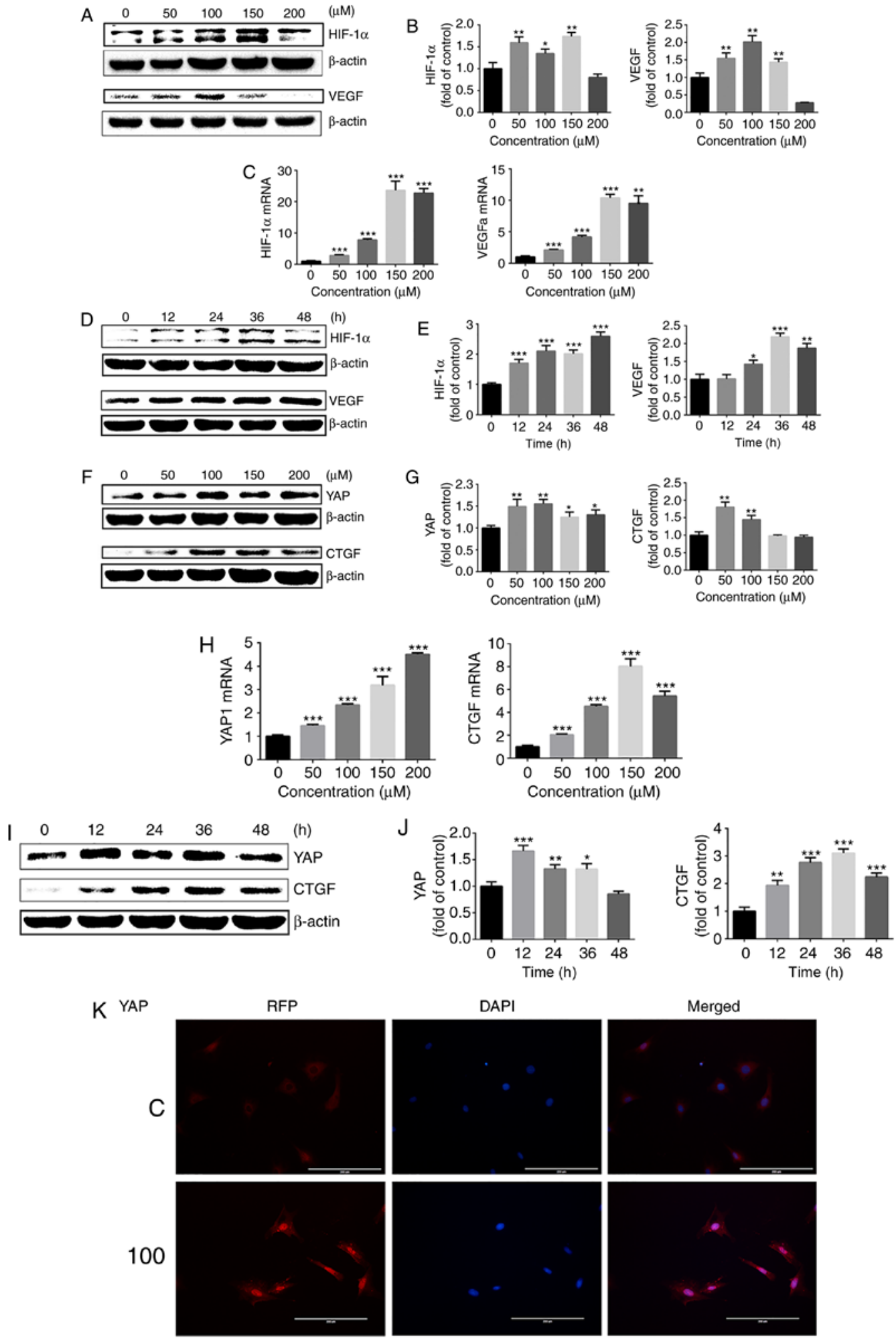

Figure 4. Cobalt chloride upregulates HIF-1 $\alpha$ expression and promotes activation of YAP. (A) Protein expression of HIF-1 $\alpha$ and VEGF in growth plate chondrocytes cultured with cobalt chloride at concentrations in $0,50,100,150$ or $200 \mu \mathrm{M}$ under normoxia $\left(21 \% \mathrm{O}_{2}\right)$ for $24 \mathrm{~h}$. $\beta$-actin served as an internal control. (B) The density of the bands was quantified and normalized to the $0 \mu \mathrm{M}$ group. (C) mRNA expression of HIF-1 $\alpha$ and VEGF in chondrocytes cultured with cobalt chloride at concentrations of $0,50,100,150$ or $200 \mu \mathrm{M}$ under normoxia $\left(21 \% \mathrm{O}_{2}\right)$ for $24 \mathrm{~h}$. (D) Protein expression of HIF-1 $\alpha$ and VEGF in growth plate chondrocytes cultured with $100 \mu \mathrm{M}$ cobalt chloride for $0,12,24,36$ or $48 \mathrm{~h}$ under normoxia $\left(21 \% \mathrm{O}_{2}\right)$. $\beta$-actin served as an internal control. (E) The density of the bands was quantified and normalized to the $0 \mathrm{~h}$ group. (F) Protein expression of YAP and CTGF in chondrocytes cultured with cobalt chloride at concentrations of 0,50 , 100,150 or $200 \mu \mathrm{M}$ under normoxia $\left(21 \% \mathrm{O}_{2}\right)$ for $24 \mathrm{~h}$. (G) The density of the bands was quantified and normalized to the $0 \mu \mathrm{M} \mathrm{group}$. (H) mRNA expression of YAP and CTGF in growth plate chondrocytes cultured with cobalt chloride at concentrations of $0,50,100,150$ or $200 \mu \mathrm{M}$ under normoxia $\left(21 \% \mathrm{O}_{2}\right)$ for $24 \mathrm{~h}$. (I) Protein expression of YAP and CTGF in growth plate chondrocytes cultured with $100 \mu \mathrm{M}$ cobalt chloride for $0,12,24,36$ or $48 \mathrm{~h}$ under normoxia (21\% $\mathrm{O}_{2}$ ). $\beta$-actin served as an internal control. (J) The density of the bands was quantified and normalized to the $0 \mathrm{~h}$ group. (K) Immunofluorescence imaging of YAP (red) in chondrocytes cultured with $100 \mu \mathrm{M}$ cobalt chloride under normoxia $\left(21 \% \mathrm{O}_{2}\right)$ for $24 \mathrm{~h}$. ' $\mathrm{C}$ ' represents the control. DAPI (blue) was used for nuclear staining. Scale bar $=200 \mu \mathrm{m}$. Data are presented as mean \pm standard deviation $(\mathrm{n}=3)$ and normalized to the control $(0 \mu \mathrm{M} / 0 \mathrm{~h})$ groups. ${ }^{*} \mathrm{P}<0.05,{ }^{* * *} \mathrm{P}<0.01$ and ${ }^{* * * *} \mathrm{P}<0.001$ vs. the $0 \mathrm{~h} / 0 \mu \mathrm{M}$ groups. YAP, yes-associated protein; HIF-1 $\alpha$, hypoxia-inducible factor $1 \alpha$; SOX9, sex-determining region-box 9 protein; NO, normoxia; HY, hypoxia; RFP, red fluorescent protein; VEGF, vascular endothelial growth factor; CTGF, connective tissue growth factor; NC, negative control. 

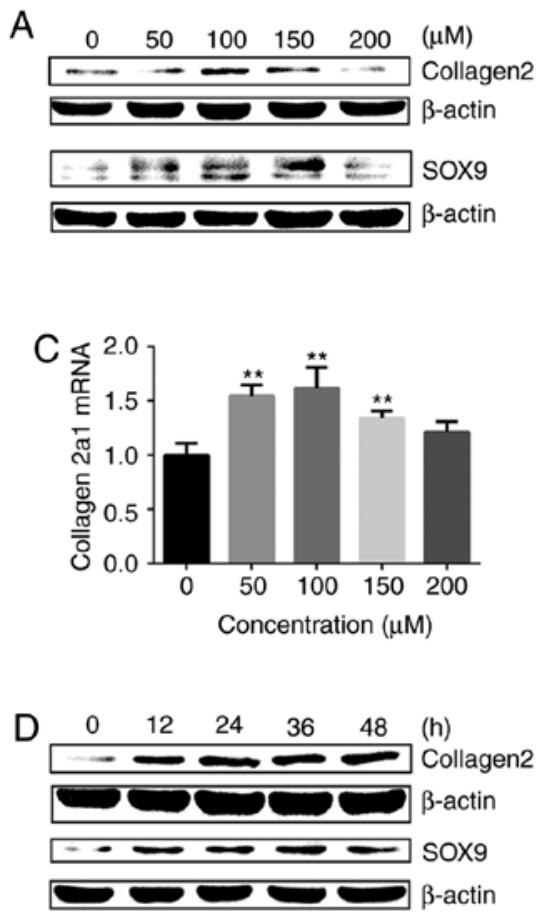
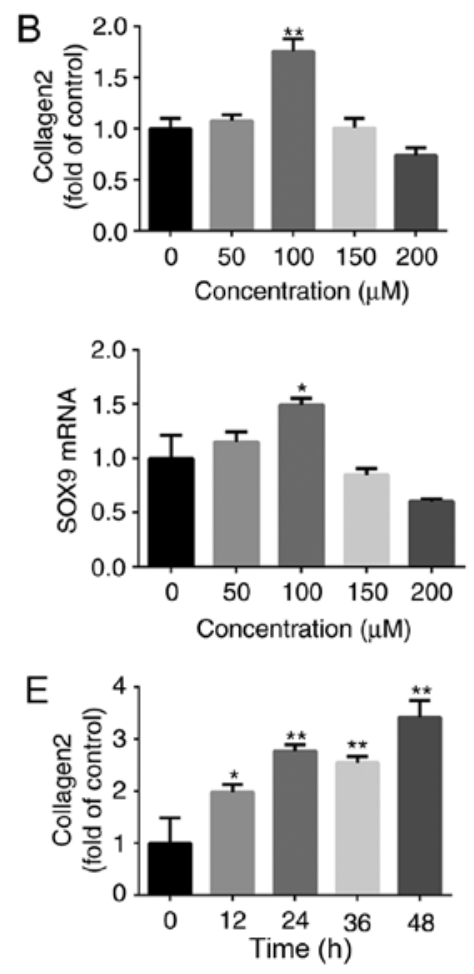
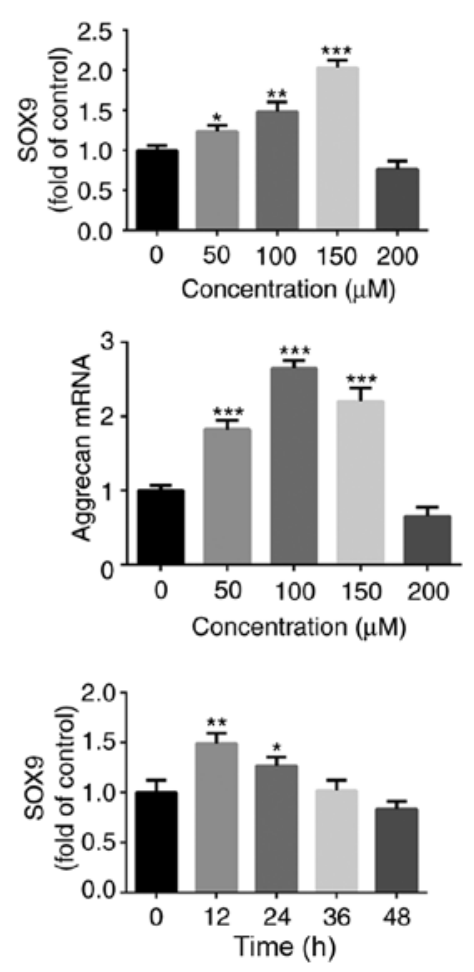

Figure 5. HIF-1 $\alpha$ is important for maintaining of the chondrogenic phenotype. (A) Protein expression of SOX9 and collagen II chain in growth plate chondrocytes cultured with cobalt chloride at concentrations of $0,50,100,150$ or $200 \mu \mathrm{M}$ under normoxia $\left(21 \% \mathrm{O}_{2}\right)$ for $24 \mathrm{~h}$. $\beta$-actin served as an internal control. (B) The density of the bands was quantified and normalized to the $0 \mu \mathrm{M}$ group. (C) mRNA expression of collagen $\alpha$-1(II) chain, SOX9 and aggrecan in chondrocytes cultured with cobalt chloride at concentrations of $0,50,100,150$ or $200 \mu \mathrm{M}$ under normoxia $\left(21 \% \mathrm{O}_{2}\right)$ for $24 \mathrm{~h}$. (D) Protein expression of SOX9 and collagen II chain in growth plate chondrocytes cultured with $100 \mu \mathrm{M}$ cobalt chloride for $0,12,24,36$ or $48 \mathrm{~h}$ under normoxia $\left(21 \% \mathrm{O}_{2}\right)$. $\beta$-actin served as an internal control. (E) The density of the bands was quantified and normalized to the $0 \mathrm{~h}$ group. Data are presented as mean \pm standard deviation ( $\mathrm{n}=3$ ), and normalized to the control $(0 \mu \mathrm{M} / 0 \mathrm{~h})$ groups. ${ }^{~} \mathrm{P}<0.05,{ }^{* *} \mathrm{P}<0.01$ and ${ }^{* * * *} \mathrm{P}<0.001$ vs. the control $(0 \mathrm{~h} / 0 \mu \mathrm{M})$ group. HIF-1 $\alpha$, hypoxia-inducible factor $1 \alpha$; SOX 9 , sex-determining region-box 9 protein.
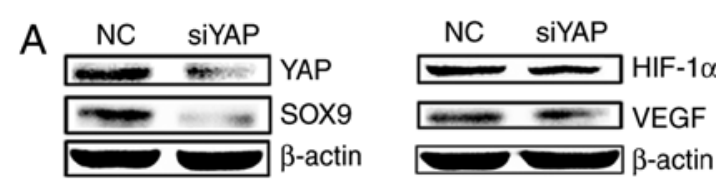
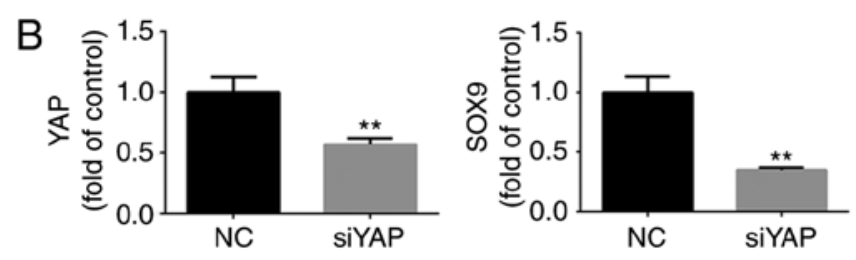
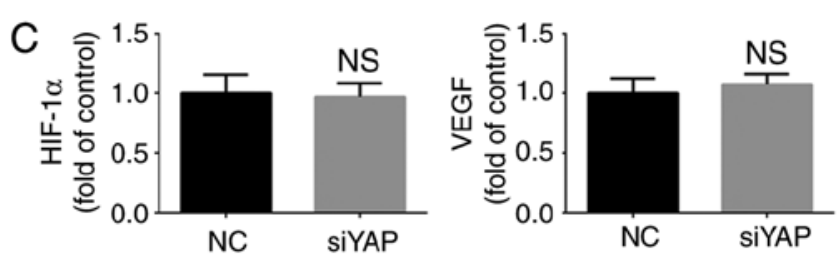

D HONO H4NO H4N1
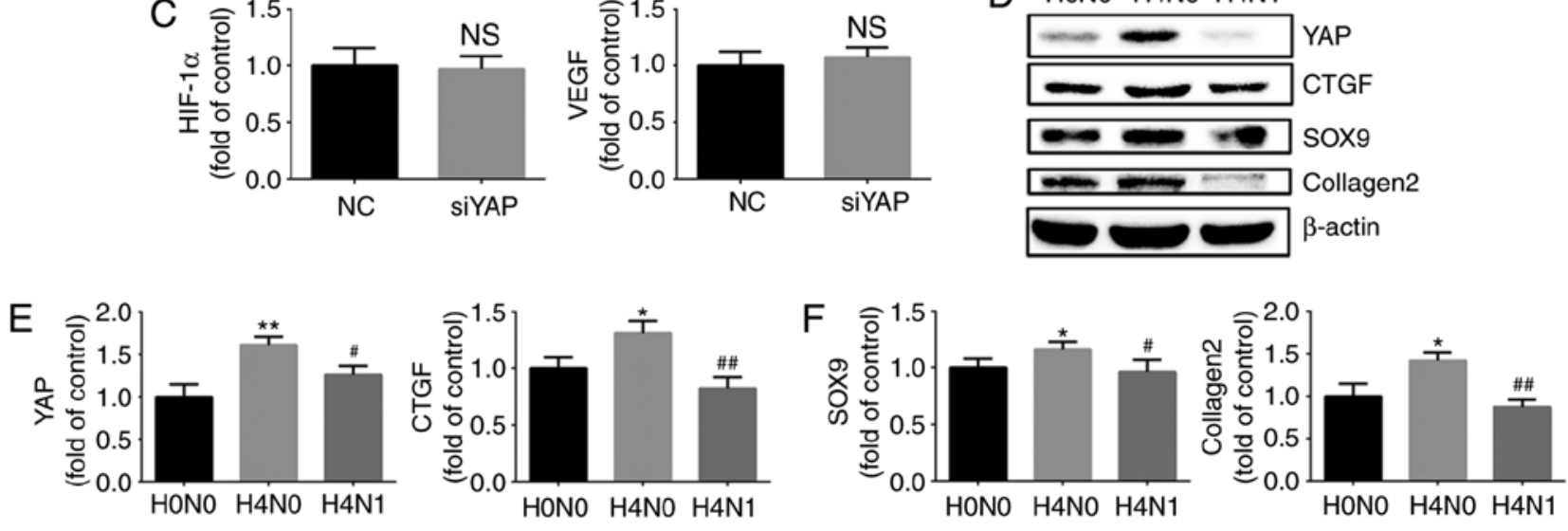

Figure 6. Effect of YAP on HIF-1 $\alpha$ and the maintenance of the chondrogenic phenotype. (A) Protein expression of YAP, SOX9, HIF-1 $\alpha$ and VEGF in growth plate chondrocytes following siRNA silencing of YAP and culture under hypoxia $\left(1 \% \mathrm{O}_{2}\right)$ for $4 \mathrm{~h}$. $\beta$-actin served as an internal control. The densities of the (B) YAP and SOX9 bands, and (C) HIF-1 $\alpha$ and VEGF bands were quantified and normalized to the NC group. (D) Protein expression of YAP, CTGF, SOX9 and collagen II chain in growth plate chondrocytes cultured under normoxia (HON0), or with (H4N1) or without reoxygenation for $1 \mathrm{~h}$ after hypoxia for $4 \mathrm{~h}$ (H4N0). $\beta$-actin served as an internal control. (E) The densities of the YAP and CTGF bands, and (F) SOX9 and collagen II chain bands were quantified and normalized to the HON0 group. Data are presented as the mean \pm standard deviation $(\mathrm{n}=3)$. ${ }^{*} \mathrm{P}<0.05$ and ${ }^{* * *} \mathrm{P}<0.01 \mathrm{vs}$. the NC/H0N0 groups. ${ }^{*} \mathrm{P}<0.05$ and ${ }^{\# \#} \mathrm{P}<0.01$ vs. the H4N0 group. YAP, yes-associated protein; HIF-1 $\alpha$, hypoxia-inducible factor $1 \alpha$; SOX9, sex-determining region-box 9 protein; CTGF, connective tissue growth factor; VEGF, vascular endothelial growth factor; siRNA, small interfering RNA; NC, negative control. 
activity and is regulated by intracellular oxygen concentration. HIF-1 $\beta$ is a structural subunit that is stably expressed and not regulated by oxygen concentration (23). Under normoxic conditions, HIF-1 $\alpha$ binds to Von Hippel-Lindau proteins, is recognized by the ubiquitin ligase E3 receptor and forms an E3 ubiquitin ligase complex, followed by ubiquitination and degradation. When the oxygen concentration decreases, HIF- $\alpha$ increases in stability and forms a heterodimer with HIF- $\beta$, which is then translocated to the nucleus to regulate downstream gene expression (23). It was previously demonstrated that HIFs may directly regulate the expression and activity of Ras homolog (Rho) gene family, member A and Rho-associated protein kinase in hypoxic breast cancer cells, thereby affecting cell contraction, cell-induced matrix contraction, FA formation, focal adhesion kinase activation and increased cell motility (24). HIF-1 $\alpha$ serves an important role in energy supply, erythropoiesis, angiogenesis and cell survival under hypoxia. Pathological hypoxia in vitro promotes the proliferation of neural stem cells (NSCs), upregulates the expression of HIF-1 $\alpha$ and activates the Wnt signaling pathway. Silencing HIF-1 $\alpha$ decreases the nuclear translocation of $\beta$-catenin and the expression of cyclin D1, and inhibits the proliferation of NSCs (25). HIF-1 serves an important role in the normal growth and development of cartilage, energy metabolism and survival $(6,26,27)$. In the present study, hypoxia promoted the expression of HIF-1 $\alpha$ in chondrocytes in a time-dependent manner, and cobalt chloride stabilized HIF-1 $\alpha$ activity and induced the expression of downstream genes under normoxic conditions in a dose- and time-dependent manner. When the concentration of cobalt chloride was $>100 \mu \mathrm{M}$, it induced cytotoxicity, and led to a downregulation of HIF-1 $\alpha$ and VEGF. When the HIF-1 $\alpha$ gene of growth plate chondrocytes was knocked out in vitro, their proliferation capacity was significantly decreased and the number of apoptotic cells increased $(28,29)$. In chondrocytes, HIF-1 $\alpha$ is involved in anaerobic metabolism and inhibits cell apoptosis under hypoxic conditions (30); it is also crucial for the differentiation of mesenchymal stem cells (MSCs) into chondrocytes $(29,31)$. Hypoxia may promote the expression of collagen II chain and proteoglycan through HIF-1 $\alpha$ and promote the anabolic metabolism of chondrocytes (16). In the present study, $1 \% \mathrm{O}_{2}$ was used to stimulate the growth plate chondrocytes, and hypoxia was identified to promote the protein and gene expression of collagen II chain and aggrecan in a time-dependent manner. When cobalt chloride was used to upregulate the expression of HIF-1 $\alpha$ under normoxic conditions, the expression of collagen II chain was also upregulated. Under hypoxic conditions, the inhibition of HIF-1 $\alpha$ by siRNA decreased the upregulation of collagen II chain induced by hypoxia. This suggested that hypoxia-induced upregulation of collagen II chain is associated with activation of HIF-1 $\alpha$. Examination of reoxygenation post-hypoxia revealed that this hypoxia-induced increase in collagen II chain expression in chondrocytes was reversible. It was previously demonstrated that, when human MSCs were stimulated by hypoxia or HIF-1 $\alpha$ in vitro, the expression of collagen II chain and proteoglycans increased, and collagen $\alpha-1(\mathrm{X})$ chain synthesis decreased. When the HIF-1 $\alpha$ stimulation was removed, collagen II chain and proteoglycan expression decreased and collagen $\alpha-1(X)$ chain synthesis was increased (32). In chondritis, HIF-1 $\alpha$ was indicated to protect chondrocytes from inflammatory factors (33).
SOX9 is a major regulator of early chondrogenic differentiation and may promote chondrocyte differentiation and interact with transcription factors SOX5 and SOX6 to promote the proliferation and differentiation of chondrocytes followed by expression of chondrocyte matrix components, including aggrecan and collagen II chain. HIF-1 $\alpha$ regulates the formation of chondrocytes by upregulating the expression of SOX9 $(34,35)$. In bone marrow MSCs, hypoxia increased the nuclear accumulation of HIF-1 $\alpha$ and SOX9 gene transcription (36). The present study demonstrated that hypoxia upregulated SOX9 expression in chondrocytes in a time-dependent and a HIF-1 $\alpha$-dependent manner.

The Hippo signaling pathway serves an important role in controlling the size and tissue regeneration in several organs, and may regulate cell proliferation and differentiation $(35,37)$. When the classical Hippo signaling is activated, MST1/2 phosphorylates and interacts with protein salvador homolog 1 to phosphorylate LATS1/2 kinase; activated LAS1/2 kinase phosphorylates YAP, resulting in its inactivation; $p$-YAP then binds to 14-3-3, followed by proteasomal degradation of the ubiquitinated protein (38). Dephosphorylated YAP enters the nucleus and interacts with Transcriptional enhancer factor TEF family of transcription factors to induce the expression of the target genes $(34,37)$. An increasing number of studies have demonstrated that Hippo signaling plays an important role in stem cell proliferation and differentiation (39). YAP has been indicated to be involved in the regulation of various cellular processes, including mechanical conduction (40) and stem cell differentiation (41). YAP regulates a series of biological behaviors including self-renewal and proliferation of stem cells $(37,42)$. However, the role of the Hippo signaling pathway in chondrocyte differentiation and bone repair remains unclear. YAP1 may directly regulate the expression of SOX6 to promote the proliferation of chondrocytes (43), and inhibit the expression of collagen $\alpha-1(X)$ chain by interacting with runt-related transcription factor 2 (Runx2) to inhibit chondrocyte maturation (44). In the growth plate of the mouse embryo, YAP1 is expressed in the resting and proliferating layers, while p-YAP1 is expressed in the hypertrophic layer, and the expression of collagen $\alpha-1(\mathrm{X})$ chain and Runx2 in the hypertrophic layer is marked (43). YAP1 is required for the proliferation and maintenance of chondrogenic progenitor cells. The overexpression of YAP1 may increase the proliferation of chondrocytes, but inhibit their differentiation. In addition, YAP1 may inhibit chondrocyte maturation and endochondral ossification during bone development and growth (43). YAP1 suppresses chondrogenic differentiation in MSCs, and the downregulation of YAP expression contributes to the chondrogenic differentiation of MSCs (22). However, the number of studies on the interaction between hypoxia and YAP is limited, particularly in chondrocytes. It has been demonstrated that hypoxia may induce YAP phosphorylation in ECO cell lines and downregulate total YAP expression (45). Hypoxia in prostate cancer increases YAP activity by increasing or decreasing YAP expression in the nucleus and lowering p-YAP levels (46). In the present study, hypoxia was used to stimulate growth plate chondrocytes, and it was identified that hypoxia upregulates the expression of YAP while Hippo signaling pathway was activated concomitantly, indicating that hypoxia promoted YAP activation via a Hippo-independent 
pathway. The RT-qPCR results also demonstrated that hypoxia may promote the upregulation of YAP mRNA expression. The results of the immunofluorescence assay revealed that the expression of YAP was significantly upregulated under hypoxic conditions, and there was marked expression in the nucleus. Reoxygenation of the chondrocytes following treatment with hypoxia demonstrated that the activation of YAP caused by hypoxia was significantly inhibited. The use of siRNA to inhibit YAP expression under hypoxic conditions decreased the expression of SOX9, indicating that SOX9 expression in hypoxia may be regulated by YAP.

Studies on the interactions between HIF-1 $\alpha$ and YAP under hypoxia are infrequent. It has been suggested that hypoxia may inactivate Hippo signaling, upregulate YAP expression and promote the formation of a complex with HIF-1 $\alpha$, thereby stabilizing the expression of HIF-1 $\alpha$ in tumors in vivo (47). In an additional study, interference with YAP in liver sinusoidal endothelial cells significantly downregulated HIF-1 protein expression (48). The present study used siRNA to inhibit the expression of HIF-1 $\alpha$ and identified that the upregulation of YAP expression caused by hypoxia was significantly inhibited. When cobalt chloride was applied to stabilize HIF-1 $\alpha$ expression under normoxic conditions, the expression of YAP and CTGF was also significantly upregulated. The treatment of chondrocytes with cobalt chloride also promoted YAP expression and nuclear translocation, as demonstrated by immunofluorescence assays. Therefore, we hypothesized that hypoxia-induced activation of YAP is HIF- $1 \alpha$-dependent. When siRNAs were used to downregulate YAP expression, the same inhibition was also observed in the upregulation of SOX9 expression induced by hypoxia. However, there was no significant effect on the HIF-1 $\alpha$ signaling pathway. Upon reoxygenation of chondrocytes following exposure to hypoxia, it was identified that the activation of YAP caused by hypoxia was significantly inhibited, and the upregulation of SOX9 and collagen II chain caused by hypoxia was also significantly inhibited. Therefore, we hypothesized that the activation of YAP serves a key role in the maintenance of the chondrogenic phenotype in hypoxia, and is closely associated with the activation of HIF-1 $\alpha$.

Hypoxia may promote the HIF-1 $\alpha$-dependent activation of YAP; this activation does not depend on Hippo signaling and is reversible. Hypoxia promotes the maintenance of the chondrogenic phenotype in a time- and HIF-1 $\alpha$-dependent manner. Inhibiting the activation of YAP under hypoxia does not affect the HIF-1 $\alpha$ signaling pathway, but inhibits the maintenance of the chondrogenic phenotype. Notably, the present study demonstrated that hypoxia ultimately affects the maintenance of the chondrogenic phenotype in growth plate chondrocytes through the interaction between HIF-1 $\alpha$ and YAP.

\section{Acknowledgements}

Not applicable.

\section{Funding}

The present study was supported by the National Natural Science Foundation of China (grant no. 51537004) and (grant no. 81702155).

\section{Availability of data and materials}

All data generated or analyzed during this study are included in this published article.

\section{Authors' contributions}

HL and XL performed the hypoxia intervention, drugs treatments, RNA interference, western blot analysis and immunofluorescence assays, and were major contributors in writing the manuscript. XJ and JC performed the chondrocytes isolation and culture. ML and YR performed the reverse transcription quantitative polymerase chain reaction and analyzed the data. CY analyzed the data FG and HW designed the experiments, revised the paper and submitted the final versions. All authors read and approved the final manuscript.

\section{Ethics approval and consent to participate}

The present study was approved by the Experimental Animal Ethics Committee of Tongji Hospital, Tongji Medical College of Huazhong University of Science and Technology (Wuhan, China).

\section{Patient consent for publication}

Not applicable.

\section{Competing interests}

The authors declare that they have no competing interests.

\section{References}

1. Makris EA, Gomoll AH, Malizos KN, Hu JC and Athanasiou KA: Repair and tissue engineering techniques for articular cartilage. Nat Rev Rheumatol 11: 21-34, 2015.

2. Caron MM, Emans PJ, Coolsen MME, Voss L, Surtel DAM, Cremers A, van Rhijn LW and Welting TJ: Redifferentiation of dedifferentiated human articular chondrocytes: Comparison of 2D and 3D cultures. Osteoarthr Cartilage 20: 1170-1178, 2012.

3. Duan L, Ma B, Liang Y, Chen J, Zhu W, Li M and Wang D: Cytokine networking of chondrocyte dedifferentiation in vitro and its implications for cell-based cartilage therapy. Am J Transl Res 7: 194-208, 2015.

4. Darling EM and Athanasiou KA: Rapid phenotypic changes in passaged articular chondrocyte subpopulations. J Orthop Res 23: 425-432, 2005.

5. Duval E, Leclercq S, Elissalde JM, Demoor M, Galéra P and Boumédiene K: Hypoxia-inducible factor 1alpha inhibits the fibroblast-like markers type I and type III collagen during hypoxia-induced chondrocyte redifferentiation: Hypoxia not only induces type II collagen and aggrecan, but it also inhibits type I and type III collagen in the hypoxia-inducible factor lalpha-dependent redifferentiation of chondrocytes. Arthritis Rheum 60: 3038-3048, 2009.

6. Schipani E, Ryan HE, Didrickson S, Kobayashi T, Knight M and Johnson RS: Hypoxia in cartilage: HIF-1alpha is essential for chondrocyte growth arrest and survival. Gene Dev 15: 2865-2876, 2001.

7. Brucker PU, Izzo NJ and Chu CR: Tonic activation of hypoxia-inducible factor 1alpha in avascular articular cartilage and implications for metabolic homeostasis. Arthritis Rheum 52: 3181-3191, 2005.

8. Schrobback K, Klein TJ, Crawford R, Upton Z, Malda J and Leavesley DI: Effects of oxygen and culture system on in vitro propagation and redifferentiation of osteoarthritic human articular chondrocytes. Cell Tissue Res 347: 649-663, 2012. 
9. Mhanna R, Öztürk E, Schlink P and Zenobi-Wong M: Probing the microenvironmental conditions for induction of superficial zone protein expression. Osteoarthr Cartilage 21: 1924-1932. 2013.

10. Mennan C, Garcia J, McCarthy H, Owen S, Perry J, Wright K, Banerjee R, Richardson JB and Roberts S: Human articular chondrocytes retain their phenotype in sustained hypoxia while normoxia promotes their immunomodulatory potential. Cartilage: Apr 1, 2018 (Epub ahead of print).

11. Robins JC, Akeno N, Mukherjee A, Dalal RR, Aronow BJ, Koopman P and Clemens TL: Hypoxia induces chondrocyte-specific gene expression in mesenchymal cells in association with transcriptional activation of Sox9. Bone 37: 313-322, 2005.

12. Koay EJ and Athanasiou KA: Hypoxic chondrogenic differentiation of human embryonic stem cells enhances cartilage protein synthesis and biomechanical functionality. Osteoarthr Cartilage 16: 1450-1456, 2008.

13. Kawato Y, Hirao M, Ebina K, Tamai N, Shi K, Hashimoto J, Yoshikawa $\mathrm{H}$ and Myoui A: Nkx3.2-induced suppression of Runx2 is a crucial mediator of hypoxia-dependent maintenance of chondrocyte phenotypes. Biochem Biophys Res Commun 416 205-210, 2011.

14. Maes C, Carmeliet G and Schipani E: Hypoxia-driven pathways in bone development, regeneration and disease. Nat Rev Rheumatol 8: 358-366, 2012 .

15. Thoms BL, Dudek KA, Lafont JE and Murphy CL: Hypoxia promotes the production and inhibits the destruction of human articular cartilage. Arthritis Rheum 65: 1302-1312, 2013.

16. Markway BD, Cho $\mathrm{H}$ and Johnstone B: Hypoxia promotes redifferentiation and suppresses markers of hypertrophy and degeneration in both healthy and osteoarthritic chondrocytes. Arthritis Res Ther 15: R92-R92, 2013.

17. Coyle CH, Izzo NJ and Chu CR: Sustained hypoxia enhances chondrocyte matrix synthesis. J Orthop Res 27: 793-799, 2009.

18. Pfander D, Cramer T, Schipani E and Johnson RS: HIF-lalpha controls extracellular matrix synthesis by epiphyseal chondrocytes. J Cell Sci 116: 1819-1826, 2003.

19. Villemure I and Stokes IA: Growth plate mechanics and mechanobiology. A survey of present understanding. J Biomech 42 1793-1803, 2009

20. Heallen T, Morikawa Y, Leach J, Tao G, Willerson JT, Johnson RL and Martin JF: Hippo signaling impedes adult heart regeneration. Development 140: 4683-4690, 2013.

21. Halder G and Johnson RL: Hippo signaling: Growth control and beyond. Development 138: 9-22, 2011.

22. Yang B, Sun H, Song F, Yu M, Wu Y and Wang J: YAP1 negatively regulates chondrocyte differentiation partly by activating the $\beta$-catenin signaling pathway. Int J Biochem Cell Biol 87: 104-113, 2017.

23. Loboda A, Jozkowicz A and Dulak J: HIF-1 versus HIF-2-is one more important than the other? Vasc Pharmacol 56: 245-251, 2012.

24. Gilkes DM, Xiang L, Lee SJ, Chaturvedi P, Hubbi ME, Wirtz D and Semenza GL: Hypoxia-inducible factors mediate coordinated RhoA-ROCK1 expression and signaling in breast cancer cells. Proc Natl Acad Sci USA 111: E384-E393, 2014.

25. Qi C, Zhang J, Chen X, Wan J, Wang J, Zhang P and Liu Y: Hypoxia stimulates neural stem cell proliferation by increasing HIF- $1 \alpha$ expression and activating Wnt $/ \beta$-catenin signaling. Cell Mol Biol (Noisy-le-grand) 63: 12-19, 2017.

26. Zhang C, Li Y, Cornelia R, Swisher S and Kim H: Regulation of VEGF expression by HIF- $1 \alpha$ in the femoral head cartilage following ischemia osteonecrosis. Sci Rep 2: 650, 2012.

27. Lefebvre V and Smits P: Transcriptional control of chondrocyte fate and differentiation. Birth Defects Res C Embryo Today 75: 200-212, 2005

28. Saito T, Fukai A, Mabuchi A, Ikeda T, Yano F, Ohba S, Nishida N, Akune T, Yoshimura N, Nakagawa T, et al: Transcriptional regulation of endochondral ossification by HIF-2alpha during skeletal growth and osteoarthritis development. Nat Med 16: 678-686, 2010.

29. Amarilio R, Viukov SV, Sharir A, Eshkar-Oren I, Johnson RS and Zelzer E: HIFlalpha regulation of Sox9 is necessary to maintain differentiation of hypoxic prechondrogenic cells during early skeletogenesis. Development 134: 3917-3928, 2007.
30. Kosyna FK, Nagel M, Kluxen L, Kraushaar K and Depping R The importin $\alpha / \beta$-specific inhibitor Ivermectin affects HIF-dependent hypoxia response pathways. Biol Chem 396: 1357-1367, 2015

31. Provot S, Zinyk D, Gunes Y, Kathri R, Le Q, Kronenberg HM, Johnson RS, Longaker MT, Giaccia AJ and Schipani E: Hif-1alpha regulates differentiation of limb bud mesenchyme and joint development. J Cell Biol 177: 451-464, 2007.

32. Duval E, Baugé C, Andriamanalijaona R, Bénateau H, Leclercq S, Dutoit S, Poulain L, Galéra P and Boumédiene K: Molecular mechanism of hypoxia-induced chondrogenesis and its application in in vivo cartilage tissue engineering. Biomaterials 33: 6042-6051, 2012.

33. Morais-Faria K, Menegussi G, Marta G, Fernandes PM, Dias RB, Ribeiro AC, Lopes MA and Cernea CR, Brandão TB and Santos-Silva AR: Dosimetric distribution to the teeth of patients with head and neck cancer who underwent radiotherapy. Oral Surg Oral Med Oral Pathol Oral Radiol 120: 416-419, 2015.

34. Zhao B, Tumaneng K and Guan KL: The Hippo pathway in organ size control, tissue regeneration and stem cell self-renewal. Nat Cell Biol 13: 877-883, 2011.

35. Yu FX, Zhao B and Guan KL: Hippo pathway in organ size control, tissue homeostasis, and cancer. Cell 163: 811-828, 2015.

36. Studer L, Csete M, Lee SH, Kabbani N, Walikonis J, Wold B and McKay R: Enhanced proliferation, survival, and dopaminergic differentiation of CNS precursors in lowered oxygen. J Neurosci 20: 7377-7383, 2000.

37. Ramos A and Camargo FD: The Hippo signaling pathway and stem cell biology. Trends Cell Biol 22: 339-346, 2012.

38. Zhao B, Wei X, Li W, Udan RS, Yang Q, Kim J, Xie J, Ikenoue T, Yu J, Li L, et al: Inactivation of YAP oncoprotein by the Hippo pathway is involved in cell contact inhibition and tissue growth control. Gene Dev 21: 2747-2761, 2007.

39. Liu H, Jiang D, Chi F and Zhao B: The Hippo pathway regulates stem cell proliferation, self-renewal, and differentiation. Protein Cell 3: 291-304, 2012.

40. Dupont S, Morsut L, Aragona M,Enzo E, Giulitti S, Cordenonsi M, Zanconato F, Le Digabel J, Forcato M, Bicciato S, et al: Role of YAP/TAZ in mechanotransduction. Nature 474: 179-183, 2011.

41. Azzolin L, Zanconato F, Bresolin S, Forcato M, Basso G, Bicciato S, Cordenonsi M and Piccolo S: Role of TAZ as mediator of Wnt signaling. Cell 151: 1443-1456, 2012.

42. Byun MR, Jeong H, Bae SJ, Kim AR, Hwang ES and Hong JH: TAZ is required for the osteogenic and anti-adipogenic activities of kaempferol. Bone 50: 364-372, 2012.

43. Deng Y, Wu A, Li P, Li G, Qin L, Song H and Mak KK: Yap1 Regulates multiple steps of chondrocyte differentiation during skeletal development and bone repair. Cell Rep 14: 2224-2237, 2016.

44. Ying J, Wang P, Zhang S, Xu T, Zhang L, Dong R, Xu S, Tong P, $\mathrm{Wu} \mathrm{C}$ and Jin $\mathrm{H}$ : Transforming growth factor-betal promotes articular cartilage repair through canonical Smad and Hippo pathways in bone mesenchymal stem cells. Life Sci 192: 84-90, 2018.

45. Ma B, Chen Y, Chen L, Cheng H, Mu C, Li J, Gao R, Zhou C, Cao L, Liu J, et al: Hypoxia regulates Hippo signalling through the SIAH2 ubiquitin E3 ligase. Nat Cell Biol 17: 95-103, 2015.

46. Chen H, Chen Q and Luo Q: Expression of netrin-1 by hypoxia contributes to the invasion and migration of prostate carcinoma cells by regulating YAP activity. Exp Cell Res 349: 302-309, 2016.

47. Yan L, Cai Q and Xu Y: Hypoxic conditions differentially regulate TAZ and YAP in cancer cells. Arch Biochem Biophys 562: 31-36, 2014

48. Zhang C, Bian M, Chen X, Jin H, Zhao S, Yang X, Shao J, Chen A, Guo Q, Zhang F and Zheng S: Oroxylin A prevents angiogenesis of LSECs in liver fibrosis via inhibition of YAP/HIF-1 $\alpha$ signaling. J Cell Biochem 119: 2258-2268, 2018.

This work is licensed under a Creative Commons Attribution-NonCommercial-NoDerivatives 4.0 International (CC BY-NC-ND 4.0) License. 